\title{
Alveolar instability (atelectrauma) is not identified by arterial oxygenation predisposing the development of an occult ventilator-induced lung injury
}

Penny L Andrews², Benjamin Sadowitz ${ }^{1}$, Michaela Kollisch-Singule ${ }^{1}$, Joshua Satalin ${ }^{1 *}$, Shreyas Roy ${ }^{1}$, Kathy Snyder ${ }^{1}$, Louis A Gatto ${ }^{3}$, Gary F Nieman ${ }^{1}$ and Nader M Habashi ${ }^{3}$

\footnotetext{
* Correspondence: satalinj@upstate. edu

${ }^{1}$ Department of Surgery, SUNY Upstate Medical University, 750 East Adams Street, Syracuse, NY 13210, USA

Full list of author information is available at the end of the article
}

\begin{abstract}
Background: Improperly set mechanical ventilation (MV) with normal lungs can advance lung injury and increase the incidence of acute respiratory distress syndrome (ARDS). A key mechanism of ventilator-induced lung injury (VILI) is an alteration in alveolar mechanics including alveolar instability or recruitment/derecruitment (R/D). We hypothesize that $\mathrm{R} / \mathrm{D}$ cannot be identified by $\mathrm{PaO}_{2}$ (masking occult VILI), and if protective ventilation is not applied, ARDS incidence will increase.

Methods: Sprague-Dawley rats $(n=8)$ were anesthetized, surgically instrumented, and placed on MV. A thoracotomy was performed and an in vivo microscope attached to the pleural surface of the lung with baseline dynamic changes in alveolar size during MV recorded. Alveolar instability was induced by intra-tracheal instillation of Tween and alveolar R/D identified as a marked change in alveolar size from inspiration to expiration with increases in positive end-expiratory pressure (PEEP) levels.

Results: Despite maintaining a clinically acceptable $\mathrm{PaO}_{2}(55-80 \mathrm{mmHg})$, the alveoli remained unstable with significant $\mathrm{R} / \mathrm{D}$ at low PEEP levels. Although $\mathrm{PaO}_{2}$ consistently increased with an increase in PEEP, R/D did not plateau until PEEP was $>9 \mathrm{cmH}_{2} \mathrm{O}$.

Conclusions: $\mathrm{PaO}_{2}$ remained clinically acceptable while alveolar instability persisted at all levels of PEEP (especially PEEP $<9 \mathrm{cmH}_{2} \mathrm{O}$ ). Therefore, $\mathrm{PaO}_{2}$ levels cannot be used reliably to guide protective MV strategies or infer that VILI is not occurring. Using $\mathrm{PaO}_{2}$ to set a PEEP level necessary to stabilize the alveoli could underestimate the potential for VILI. These findings highlight the need for more accurate marker(s) of alveolar stability to guide protective MV necessary to prevent VILI.
\end{abstract}

\section{Background}

The acute respiratory distress syndrome (ARDS) remains a serious clinical challenge affecting nearly 200,000 patients annually, claiming the lives of $30-40 \%$ of those afflicted [1]. Although mechanical ventilation (MV) is applied to patients without lung injury, improperly set MV [2] can cause a secondary ventilator-induced lung injury (VILI) [3], playing a key role in the high incidence of ARDS (25\%) within $48 \mathrm{~h}$ of MV initiation $[4,5]$. Most cases of ARDS evolve over 30-72 h after hospital admission where lung protective strategies are typically implemented after the development of 
lung injury and clinically diagnosed by a deterioration of oxygenation characterized by a decline in $\mathrm{PaO}_{2} / \mathrm{FiO}_{2}(\mathrm{P} / \mathrm{F})$ ratio $[6,7]$. Although there are alternative markers of optimizing mechanical ventilation, most definitions of ARDS [6,7] rely on oxygenation $\left(\mathrm{PaO}_{2}\right)$ as a marker of pulmonary function. Lung protection is generally instituted in a reactive rather than proactive approach with an emphasis on treating rather than preventing the progression of worsening lung injury. Further, clinicians target $\mathrm{PaO}_{2}$ or saturation $\left(\mathrm{SpO}_{2}\right)$ [8] to determine if ventilator strategies are effective prior to and after the development of acute lung injury (ALI). However, reliance on $\mathrm{PaO}_{2}$ as a marker of lung function presumes there is no lung injury prior to ARDS perpetuating a binary concept of ARDS. A key to understanding lung-ventilator interactions may lie in subclinical mechanisms of lung injury and the impact of MV on the "micro-environment" at the alveolar/alveolar duct level rather than centering on the "macro-environment" and parameters displayed on the ventilator (i.e., tidal volume $(\mathrm{Vt})$, plateau pressure) using $\mathrm{PaO}_{2}$ and $\mathrm{SpO}_{2}$.

Recently, it has been suggested that the primary mechanism of VILI is tidal alveolar recruitment/derecruitment (R/D) $[9,10]$. Our group has shown that tidal R/D leads to persistent alveolar instability causing severe histologic lung injury and ARDS [11] and optimizing alveolar stability is critical to preventing VILI and limiting ARDS [12-14]. $\mathrm{PaO}_{2}$ may not be an accurate surrogate of alveolar stability; therefore, preventing ARDS using preemptive MV requires clinicians to consider the potential for occult alveolar instability (i.e., R/D without a significant fall in $\mathrm{PaO}_{2}$ ) [6]. In this study, we hypothesized that in an acutely injured lung, alveolar instability would persist despite improvements in $\mathrm{PaO}_{2}$ with increasing levels of positive end-expiratory pressure (PEEP). Lack of correlation between $\mathrm{PaO}_{2}$ and alveolar stability would provide a mechanistic explanation of why patients with normal $\mathrm{PaO}_{2}$ evolve to ARDS after $48 \mathrm{~h}$ of MV $[4,15]$. In this study, we show direct visual evidence using in vivo microscopy that alveolar R/D cannot be predicted using $\mathrm{PaO}_{2}$ as a surrogate for alveolar stability and protective MV.

\section{Methods}

\section{Vertebrate animals}

The Institutional Animal Care and Use Committee at Upstate Medical University, Syracuse, NY, approved the studies. All experiments were performed in adherence to the guidelines established by the National Institutes of Health for the use of experimental animals in research.

\section{Surgical preparation}

Adult male Sprague-Dawley rats $(n=8)$ weighing $590 \pm 19.2 \mathrm{~g}$ were anesthetized via an intraperitoneal injection of ketamine/xylazine (90 and $10 \mathrm{mg} / \mathrm{kg}$, respectively) dosed at $0.1 \mathrm{mg} / \mathrm{kg}$ of ketamine before surgery as well as during the experiment to provide adequate anesthesia. To ensure that the Vt remained constant, the animals were paralyzed with rocuronium to inhibit spontaneous breathing. A tracheostomy was performed, and time-cycled/pressure-controlled mechanical ventilation was initiated with a PEEP of $3 \mathrm{cmH}_{2} \mathrm{O}$, pressure control ( $\left.P_{\text {control }}\right)$ of $15 \mathrm{cmH}_{2} \mathrm{O}$, respiratory rate of 30 breaths/min, and $\mathrm{FiO}_{2}$ of 100 \% (Hamilton G5 ventilator, Hamilton Medical Inc., Reno, NV). A jugular vein 
was cannulated for the administration of fluids and a carotid artery catheter placed for blood gas samples and hemodynamic monitoring.

Hemodynamic, pulmonary, and blood gas measurements

Hemodynamic and pulmonary parameters were continuously monitored (Philips Healthcare and Hamilton G5 ventilator). Arterial blood gas was sampled at baseline and each PEEP level, as defined in "Lung injury," to record $\mathrm{pH}, \mathrm{PaCO}_{2}, \mathrm{PaO}_{2}$, and $\mathrm{PaO}_{2} / \mathrm{FiO}_{2}$ (P/F) ratios (cobas b221, Roche Diagnostics).

\section{Lung injury}

Serial blood gases were taken and the respiratory rate adjusted until $\mathrm{PaCO}_{2}$ was between 35 and $45 \mathrm{mmHg}$. A baseline blood gas was performed and lung injury induced via $0.2 \%$ Tween-20 in normal saline $(16 \mathrm{cc} / \mathrm{kg})$ instillation via an endotracheal tube. This was repeated until a $\mathrm{P} / \mathrm{F}<100 \mathrm{mmHg}$ was reached.

\section{In vivo microscopy}

After induction of lung injury, a right thoracotomy was performed to expose the pleural surface of the right lung. The in vivo microscope (epi-objective microscope with epiillumination; Olympus America Inc.) was approximated to the nondependent (anterior) portion of the right lung and $5 \mathrm{cmH}_{2} \mathrm{O}$ suction applied to capture a steady field of the alveoli at $\times 10$ magnification. Although dependent lung regions may be more susceptible to $R / D$, stability in dependent regions would be unlikely if alveolar stability in nondependent regions was not achieved. In this model, we used individual rats as their own control and documented alveolar stability at baseline. After Tween injury, alveolar behavior became unstable demonstrating R/D. Thirty seconds of video was recorded from an attached digital video camera (Sony CCD color video camera SSC-S20) and uploaded to a computer while maintaining a PEEP of $3 \mathrm{cmH}_{2} \mathrm{O}$ and $P_{\text {control }}$ of $15 \mathrm{cmH}_{2} \mathrm{O}$. Subsequently, PEEP was increased in $3 \mathrm{cmH}_{2} \mathrm{O}$ increments and videos recorded from the in vivo microscopy at each setting until a PEEP of $18 \mathrm{cmH}_{2} \mathrm{O}$ was achieved. This procedure was repeated at each PEEP level in five distinct parenchymal areas of the right nondependent lung.

\section{Image capture and processing}

Video was captured using Pinnacle Studio software (Corel Corp.) for analysis of alveolar mechanics. Individual frames were extracted and analyzed at the plateau pressure $\left(P_{\text {plateau }}\right)$ and peak expiration (PEEP) for five lung fields per PEEP level. The alveoli were identified in the frames and manually outlined using Photoshop CS6 (Adobe Inc.) with areas calculated using Image-Pro software (Media Cybernetics). The areas calculated represent alveolar inflation at end-inspiration (I) and endexpiration (E) and are each represented as a fraction of the total microscopic lung field. Alveolar instability was assessed by comparing the percent difference between I and $\mathrm{E}(\% \Delta \mathrm{I}-\mathrm{E})$. A greater $\% \Delta \mathrm{I}-\mathrm{E}$ is suggestive of increased $\mathrm{R} / \mathrm{D}$ and alveolar instability. 


\section{Statistics}

Least squares regression was used to determine whether alveolar stability and arterial oxygenation were linearly related (Microsoft Excel, 2008).

\section{Results}

\section{Physiologic parameters}

All animals displayed severe lung injury after Tween instillation with average P/F ratio $<100 \mathrm{mmHg}$. As PEEP was increased, there was a concomitant decrease in mean arterial pressure but no change in heart rate (Table 1 ). With increasing PEEP, there was no significant change in $\mathrm{pH}$ but there was a decrease in $\mathrm{pCO}_{2}$ with PEEP above $6 \mathrm{cmH}_{2} \mathrm{O}$. Increasing PEEP led to a correspondent increase in the mean airway pressure (Paw) and

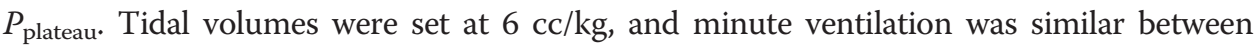
groups (Table 2).

\section{Alveolar stability and $\mathrm{PaO}_{2}$}

Subpleural alveoli at I and $\mathrm{E}$ in both the uninjured and injured lungs are seen in Fig. 1 with individual alveoli outlined in dots. Measuring alveolar size change between I and E is used to assess alveolar stability.

\section{Uninjured alveolar stability and $\mathrm{PaO}_{2}$}

There was a minimal size change during tidal ventilation in the normal lung with $12 \mathrm{cmH}_{2} \mathrm{O}$ of PEEP compared to a large change in alveolar size in the injured lung indicating severe alveolar instability even with $18 \mathrm{cmH}_{2} \mathrm{O}$ of PEEP (Fig. 1).

\section{Injured alveolar stability and $\mathrm{PaO}_{2}$}

Examination of the aggregate data shows that a stepwise increase in PEEP $\left(3-9 \mathrm{cmH}_{2} \mathrm{O}\right)$ led to an increase in both alveolar stability and $\mathrm{PaO}_{2}$ (Fig. 2). However, further increased levels of PEEP (12-18 cmH $\mathrm{cm}_{2} \mathrm{O}$ ) improved $\mathrm{PaO}_{2}$ without a concomitant increase in alveolar stability (Fig. 2). Examination of individual animals demonstrated that $\mathrm{PaO}_{2}$ remained largely unchanged despite a spectrum of alveolar instability at a given PEEP level.

\section{Discussion}

The most important findings of this study were as follows: (a) unstable alveoli oxygenated blood to nearly the same $\mathrm{PaO}_{2}$ as stable alveoli, particularly at levels of PEEP of 3-9 $\mathrm{cmH}_{2} \mathrm{O}$; (b) alveolar stability did not improve when PEEP was increased above $9 \mathrm{cmH}_{2} \mathrm{O}$ despite continual improvement in $\mathrm{PaO}_{2}$ up to PEEP of $18 \mathrm{cmH}_{2} \mathrm{O}$ (Fig. 3); and (c) combined with our prior work, this shows that PEEP may have a greater effect recruiting and distending conducting airways rather than the alveoli [16]. In a previous study, we showed increasing levels of PEEP increases micro-strain of the conducting airways with less effect on alveolar area [16]. In the present study, low levels of PEEP may have recruited collapsed conducting airways initially stabilizing communicating alveoli (steep portion of alveolar stability curve in Fig. 2). However, an increase in PEEP may have caused progressive distention in the conducting airways rather than increasing alveolar area and stability. Despite increasing PEEP, alveolar stability plateaus above PEEP of $9 \mathrm{cmH}_{2} \mathrm{O}$ and never reaches the complete stability (i.e., $\mathrm{R} / \mathrm{D}=0 \%$ ) of the 
Table 1 Hemodynamic and blood gas measurements

\begin{tabular}{|c|c|c|c|c|c|c|c|c|}
\hline & BL-uninjured & Post-injury & PEEP 3 & PEEP 6 & PEEP 9 & PEEP 12 & PEEP 15 & PEEP 18 \\
\hline HR (beats/min) & $189.1 \pm 59.1$ & $186.4 \pm 45.1$ & $204.9 \pm 44.5$ & $172.2 \pm 51.1$ & $186.0 \pm 38.3$ & $176.7 \pm 44.6$ & $179.9 \pm 61.5$ & $150.5 \pm 42.9$ \\
\hline MAP (mmHg) & $71.8 \pm 21.1$ & $61.3 \pm 12.6$ & $50.6 \pm 16.2$ & $52.5 \pm 26.5$ & $49.0 \pm 24.1$ & $47.4 \pm 18.1^{*}$ & $44.5 \pm 16.5^{*}$ & $39.1 \pm 15.7^{*}$ \\
\hline $\mathrm{pH}$ & $7.35 \pm 0.07$ & $7.246 \pm 0.087$ & $7.204 \pm 0.049^{*}$ & $7.153 \pm 0.101^{*}$ & $7.209 \pm 0.066^{*}$ & $7.197 \pm 0.109^{*}$ & $7.21 \pm 0.15^{*}$ & $7.199 \pm 0.195^{*}$ \\
\hline $\mathrm{PaCO}_{2}(\mathrm{mmHg})$ & $38.11 \pm 11.67$ & $53.58 \pm 14.43^{*}$ & $47.42 \pm 13.21$ & $49.68 \pm 11.22$ & $36.49 \pm 4.85$ & $35.43 \pm 5.99$ & $32.0 \pm 7.0$ & $29.39 \pm 7.17$ \\
\hline $\mathrm{PaO}_{2}(\mathrm{mmHg})$ & $467.5 \pm 163.5$ & $54.03 \pm 24.70^{*}$ & $60.07 \pm 13.10^{*}$ & $106.3 \pm 90.47^{*}$ & $169.7 \pm 143.5^{*}$ & $221.5 \pm 115.5^{*}$ & $266.0 \pm 122.0^{*}$ & $352.0 \pm 159.0$ \\
\hline $\mathrm{FiO}_{2}(\%)$ & 100 & 100 & 100 & 100 & 100 & 100 & 100 & 100 \\
\hline \% Saturation & $97.63 \pm 1.26$ & $56.43 \pm 20.96^{*}$ & $64.76 \pm 16.04^{*}$ & $65.12 \pm 17.54$ & $88.77 \pm 5.74$ & $92.26 \pm 8.58$ & $93.15 \pm 8.11$ & $95.1 \pm 5.98$ \\
\hline $\mathrm{P} / \mathrm{F}$ & 507.6 & $54.03^{*}$ & $60.07^{*}$ & $106.3^{*}$ & $169.7^{*}$ & $221.5^{*}$ & $266.0^{*}$ & $352.0^{*}$ \\
\hline
\end{tabular}


Table 2 Pulmonary measurements

\begin{tabular}{|c|c|c|c|c|c|c|c|c|}
\hline & BL-uninjured & Post-injury & PEEP 3 & PEEP 6 & PEEP 9 & PEEP 12 & PEEP 15 & PEEP 18 \\
\hline Vt $(\mathrm{ml}) / \mathrm{kg}$ & $6.0 \pm 0.5$ & $5.9 \pm 0.3$ & $6.0 \pm 0.5$ & $5.9 \pm 0.3$ & $5.9 \pm 0.3$ & $5.9 \pm 0.3$ & $5.9 \pm 0.3$ & $5.875 \pm 0.354$ \\
\hline$P_{\text {control }}\left(\mathrm{cmH}_{2} \mathrm{O}\right)$ & $12.6 \pm 2.5$ & $16.9 \pm 1.2^{*}$ & $17.6 \pm 2.2^{*}$ & $16.6 \pm 2.5^{*}$ & $15.5 \pm 3.1$ & $14.9 \pm 3.1$ & $14.7 \pm 3.9$ & $12.88 \pm 5.0$ \\
\hline$P_{\text {peak }}\left(\mathrm{cmH}_{2} \mathrm{O}\right)$ & $15.7 \pm 2.6$ & $20.1 \pm 1.4^{*}$ & $20.7 \pm 2.3^{*}$ & $22.5 \pm 2.3^{*}$ & $24.5 \pm 3.1^{*}$ & $27.0 \pm 3.2^{*}$ & $29.7 \pm 3.9^{*}$ & $30.88 \pm 5.0^{*}$ \\
\hline$P_{\text {plateau }}\left(\mathrm{cmH}_{2} \mathrm{O}\right)$ & $15.7 \pm 2.6$ & $20.0 \pm 1.3^{*}$ & $20.6 \pm 2.2^{*}$ & $22.6 \pm 2.5^{*}$ & $24.5 \pm 3.1^{*}$ & $27.0 \pm 3.2^{*}$ & $29.7 \pm 3.9^{*}$ & $30.88 \pm 5.0^{*}$ \\
\hline$P_{\text {mean }}\left(\mathrm{cmH}_{2} \mathrm{O}\right)$ & $6.59 \pm 0.65$ & $7.72 \pm 0.43$ & $7.94 \pm 0.72$ & $10.15 \pm 0.95^{*}$ & $11.99 \pm 1.35^{*}$ & $13.8 \pm 1.9^{*}$ & $15.3 \pm 3.6^{*}$ & $14.63 \pm 2.8^{*}$ \\
\hline MV (I/min) & $0.183 \pm 0.009$ & $0.187 \pm 0.022$ & $0.185 \pm 0.022$ & $0.184 \pm 0.026$ & $0.188 \pm 0.019$ & $0.187 \pm 0.016$ & $0.19 \pm 0.028$ & $0.175 \pm 0.018$ \\
\hline RR (breaths/min) & $30.5 \pm 1.6$ & $30.4 \pm 2.0$ & $30.9 \pm 2.5$ & $32.0 \pm 3.3$ & $32.0 \pm 3.3$ & $31.6 \pm 2.5$ & $31.4 \pm 2.9$ & $30.13 \pm 3.23$ \\
\hline
\end{tabular}




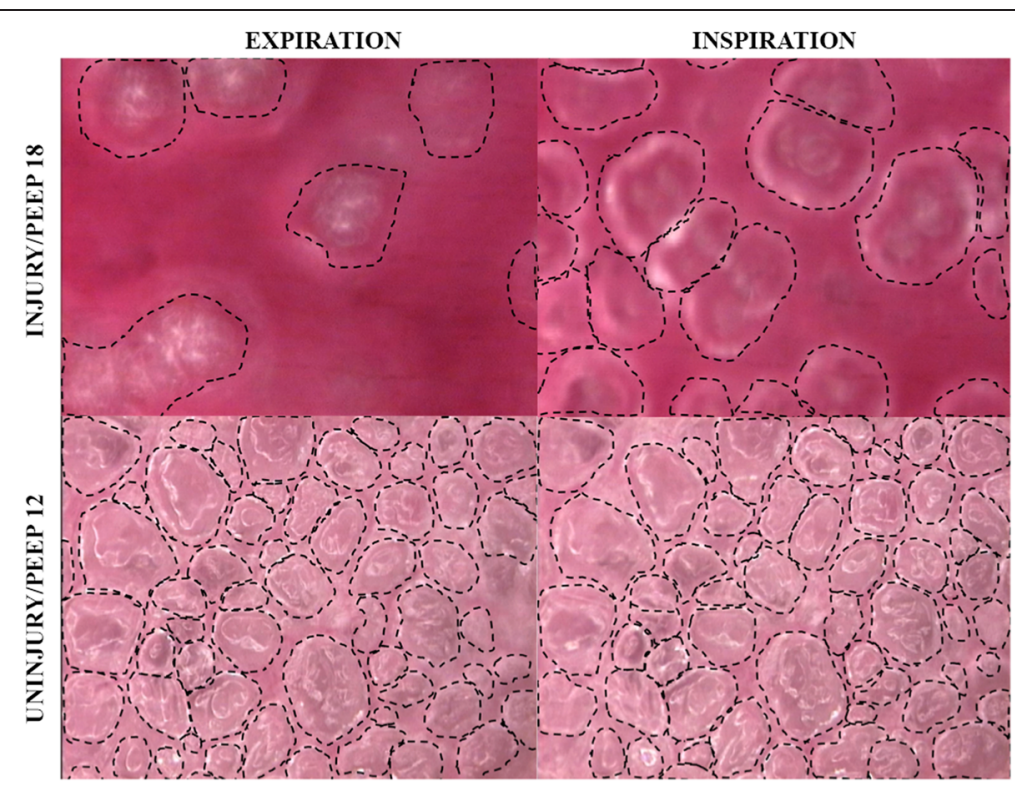

Fig. 1 In vivo microscopy showing alveolar inflation of non-injured (PEEP 12) and injured (PEEP 18) lungs at end-inspiration and end-expiration

uninjured lung [17]. These data suggest that alveolar stability has a nonlinear relationship to $\mathrm{PaO}_{2}$.

We hypothesize that improvement in $\mathrm{PaO}_{2}$ was due to end-inspiratory tidal recruitment of collapsed alveoli rather than recruitment of unstable alveoli throughout the ventilator cycle (i.e., both I and E). Oxygen would be exchanged during inspiration as the alveolus "pops" open and coupled with the rapid transit time of the erythrocyte,

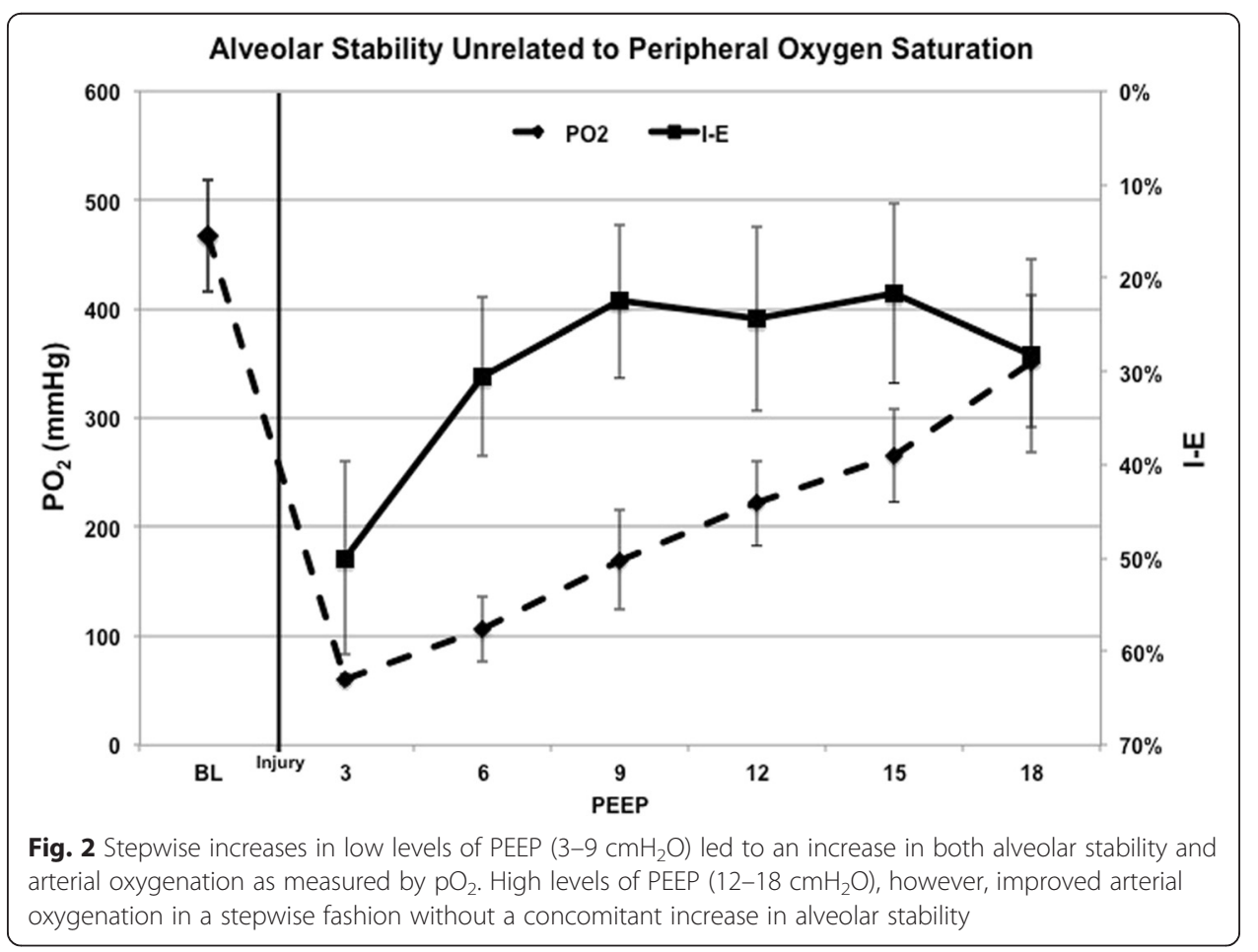




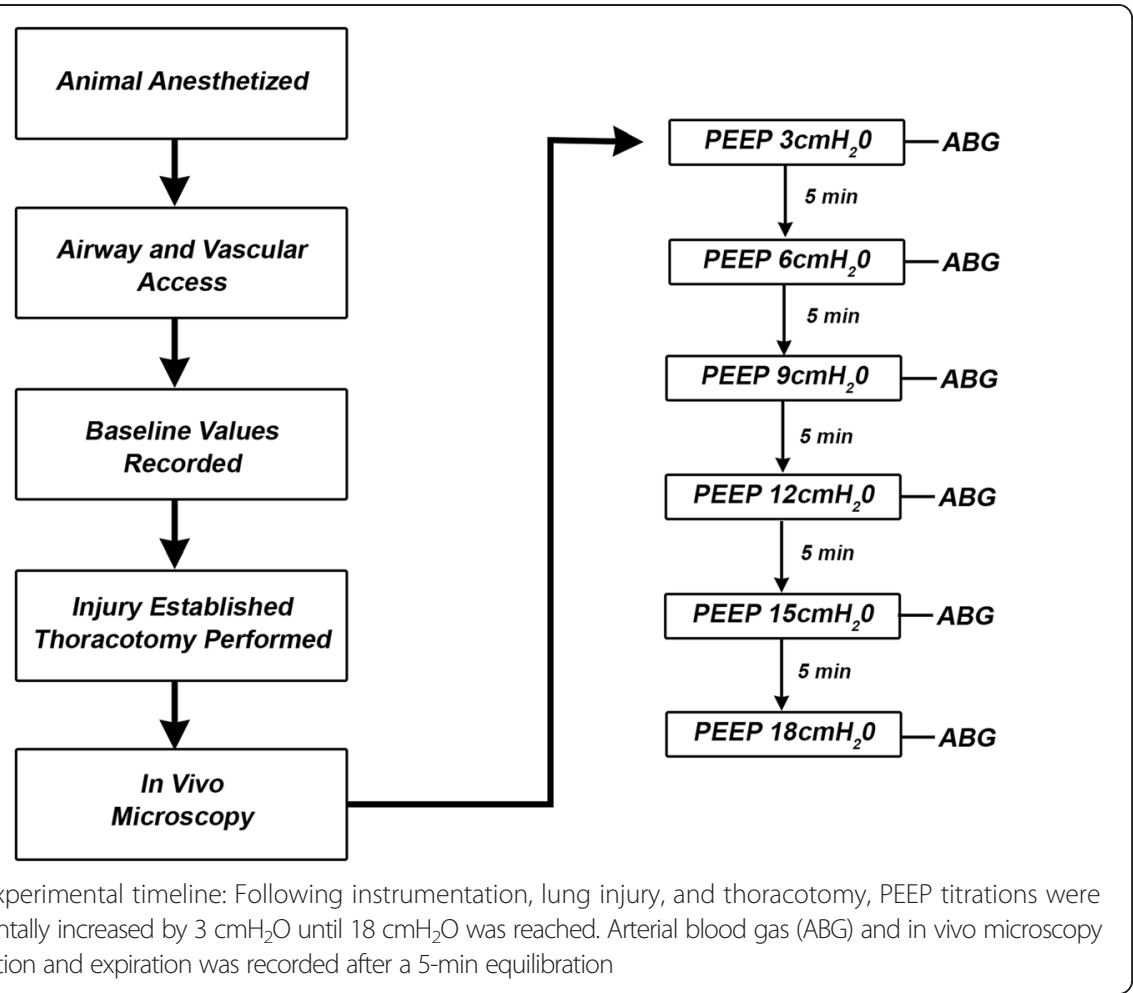

maintaining a relatively normal $\mathrm{PaO}_{2}$; however, the alveoli collapse during expiration. The linear improvement in $\mathrm{PaO}_{2}$ without a corresponding increase in alveolar stability suggests persistent alveolar instability, and the potential to expose the lung to occult VILI exists and may silently progress to clinical ARDS.

Our data and others demonstrate that perhaps the most widely used marker for lung injury $\left[\mathrm{PaO}_{2}\right]$ is insensitive to detect alveolar instability. Baumgardner et al. used a high-speed intravascular $\mathrm{PaO}_{2}$ sensor in a saline lavage ARDS model and found that $\mathrm{PaO}_{2}$ fluctuated within the respiratory cycle [18]. They postulated that $\mathrm{PaO}_{2}$ rose during inflation when the alveoli were open and fell (during exhalation) when the alveoli collapsed [18]. Using a fiber optic oxygen sensor that detects rapid $\mathrm{PaO}_{2}$ changes, Formenti and colleagues documented $\mathrm{PaO}_{2}$ fluctuations between 37 and $375 \mathrm{mmHg}$ between the I and E cycles as a result of cyclical atelectasis [19]. Caltabeloti et al. have shown, using ultrasound, that lung aeration decreases during fluid loading without any deterioration in $\mathrm{PaO}_{2}$. These data demonstrate that although oxygenation improves, alveolar R/D-induced VILI may persist but cannot be identified by standard clinical measurements (i.e., $\mathrm{PaO}_{2}$ ). Therefore, if solely guided by $\mathrm{PaO}_{2}$, ventilator adjustments may aggravate alveolar instability, particularly when lung injury is evolving secondary to volume resuscitation and a progressing systemic inflammatory response syndrome (SIRS) [20]. Furthermore, uncontrolled R/D increases lung inflammatory response and may propagate other organ dysfunctions and multisystem organ failure [21]. This potentially explains the dichotomy of results in the ARDSnet trial (i.e., improved oxygenation in the high Vt/end-inspiratory pressure group, yet an increase in mortality) [22]. The low tidal volume strategy with lower end-inspiratory pressure may have resulted in a greater regional lung collapse and lower oxygenation; but because these regions remain 
collapsed throughout the breathing cycle, they are protected from tidal R/D, resulting in less alveolar instability rather than overdistension (Fig. 2) [23].

Although recruitment maneuvers (RM) were not used in this study, previous work from this lab using in vivo microscopy demonstrated that the alveoli open following an RM but remain unstable unless combined with sufficient amounts of PEEP to maintain alveolar patency [24]. Oxygenation significantly improves following RMs despite persistent alveolar R/D, suggesting that unstable alveoli participate in oxygenation during the portion of the ventilatory cycle in which they are open [11]. RMs improve oxygenation but have not demonstrated a mortality benefit $[25,26]$ supporting our postulate that despite improved $\mathrm{PaO}_{2}$, alveolar instability may persist causing progressive lung injury. Nontraditional approaches to MV such as high-frequency oscillatory ventilation (HFOV) use similar goals of $\mathrm{PaO}_{2}$ or $\mathrm{SpO}_{2}$ to guide adjustment of ventilator settings. Two recent trials used oxygenation triggers to adjust Paw and the decision to convert from HFOV back to conventional ventilation [27, 28]. However, experimentally, we have shown that adjusting Paw during HFOV based on $\mathrm{PaO}_{2}$-guided protocols resulted in significantly greater histologic lung injury as compared with maintaining a constant Paw after lung injury [27, 28]. Combined, these data support our hypothesis that $\mathrm{PaO}_{2}$ does not correlate with alveolar stability with enough sensitivity to guide ventilator adjustments and relying solely on oxygenation to make ventilator adjustments could increase alveolar instability and promote occult VILI.

Clinically, these data may be important as discordance between $\mathrm{PaO}_{2}$ and the degree of alveolar instability creates the potential for occult R/D-induced VILI. Robust clinical markers for evaluating alveolar stability are lacking; thus, VILI remains a genuine concern among clinicians who intend to minimize iatrogenic lung injury during MV. In clinical practice, $\mathrm{PaO}_{2}$ or $\mathrm{SpO}_{2}$ is routinely used to guide ventilator adjustments [8]. The commonly used $\mathrm{PEEP} / \mathrm{FiO}_{2}$ table derived from the ARDSnet strategy links a $\mathrm{PaO}_{2}$ or $\mathrm{SpO}_{2}$ goal to regulate PEEP and $\mathrm{FiO}_{2}$. Several investigators have suggested that the $\mathrm{PEEP} / \mathrm{FiO}_{2}$ scale does not impose a physiologic end-point for clinical or computed tomography-guided evidence of recruitment and alveolar stability [29, 30]. In addition, clinicians frequently underdiagnose ARDS suggesting that acceptable oxygenation may leave many without concern for ongoing lung injury [31]. In this study, all animals had an acceptable $\mathrm{P} / \mathrm{F}$ ratio based on the $\mathrm{PEEP} / \mathrm{FiO}_{2}$ table despite a $25-60 \%$ increase in alveolar instability from baseline. This suggests that achieving clinically acceptable oxygenation goals may not equate with decreased alveolar instability, allowing persistent $\mathrm{R} / \mathrm{D}$ and the potential for VILI.

\section{Summary}

This study has identified the need of detecting alveolar instability and optimizing MV settings to promote alveolar stability and lung homogeneity using methods other than $\mathrm{PaO}_{2}$. Possible methods include the following: (a) electrical impedance tomography (EIT) which provides an assessment of lung volume, PEEP level, and Vt distribution rather than the relationship of Vt to ideal body weight [32-34]; (b) routine evaluation of the respiratory system as a whole with transpulmonary pressure measurement to determine the effect of the chest wall and abdomen on lung mechanics [35-37]; and (c) monitoring the expiratory flow graphics when using modes such as airway pressure 
release ventilation (APRV) to control expiratory time constants which has been shown to eliminate alveolar instability $[38,39]$. These methods are all currently available and may guide ventilator adjustments rather than relying on the insensitivity of $\mathrm{PaO}_{2}$ and $\mathrm{SpO}_{2}$ or the macro-environment parameter such as Paw [14, 32-39].

The concept that preemptive ventilation strategies may be therapeutic is obverse to the current understanding that MV creates or aggravates lung injury (i.e., VILI). Although both concepts may be accurate, the key may be the method of MV and the timing of application in the pathogenesis of the disease (i.e., early vs. late) $[13,14,39,40]$. The causal role of MV in progressing acute lung injury (ALI) may be determined by adjustment of ventilator settings to adequately prevent alveolar instability and heterogeneity. If adjusted properly, the ventilator may be used to halt the progression of ALI pathogenesis and reduce the incidence of ARDS [12-14, 16, 39, 40].

\section{Critique of the model}

While we speculate that the steady increase observed in $\mathrm{PaO}_{2}$ without a marked change in alveolar stability at PEEP levels of $>9 \mathrm{cmH}_{2} \mathrm{O}$ was likely due to increased alveolar recruitment, this recruitment was not confirmed by direct measurement. Also, our in vivo microscope has limitations such as the shallow depth of field $(70 \mu \mathrm{m})$, limiting observations of alveolar mechanics to only two dimensions. We used gentle suction $\left(\leq 5 \mathrm{cmH}_{2} \mathrm{O}\right.$ ) to hold lung tissue in place underneath the glass coverslip in all experimental settings standardizing this artifact, which has been shown previously to have minimal effect on alveolar mechanics [41].

\section{Conclusions}

Our data suggest that oxygenation $\left(\mathrm{PaO}_{2}\right)$ may be a poor marker for alveolar stability and occult VILI may exist despite meeting acceptable clinical criteria. Further, using $\mathrm{PaO}_{2}$ to guide titration of MV settings (PEEP and Pplat) may result in increased alveolar instability and increase the potential for VILI. New methods to identify alveolar stability are needed for clinical assessment and protection from occult VILI. In combination with judicious use of MV, the goal of eliminating VILI in the critical care population may eventually be realized.

\section{Competing interests}

The authors declare that they have no competing interests.

\section{Authors' contributions}

PLA and NMH had full access to all of the data in the study and took responsibility for the integrity of the data and the accuracy of the data analysis. PLA, BS, MK-S, JS, SR, KS, LAG, GFN, and NMH contributed substantially to the study design, data analysis and interpretation, and the writing of the manuscript. All authors read and approved the final manuscript.

Acknowledgements

Funding for this work was provided by the National Institutes of Health grant R33HL089076.

Author details

'Department of Surgery, SUNY Upstate Medical University, 750 East Adams Street, Syracuse, NY 13210, USA.

${ }^{2}$ Department of Critical Care, R Adams Cowley Shock Trauma Center, Baltimore, MD, USA. ${ }^{3}$ Department of Biology, SUNY Cortland, Cortland, NY, USA. 


\section{References}

1. Goss CH, Brower RG, Hudson LD, Rubenfeld GD, Network A (2003) Incidence of acute lung injury in the United States. Crit Care Med 31:1607-1611

2. Whitehead T, Slutsky AS (2002) The pulmonary physician in critical care * 7: ventilator induced lung injury. Thorax 57:635-642

3. Slutsky AS, Ranieri VM (2013) Ventilator-induced lung injury. N Engl J Med 369:2126-2136

4. Gajic O, Dara SI, Mendez JL, Adesanya AO, Festic E, Caples SM, Rana R, St Sauver JL, Lymp JF, Afessa B, Hubmayr RD (2004) Ventilator-associated lung injury in patients without acute lung injury at the onset of mechanical ventilation. Crit Care Med 32:1817-1824

5. Shari G, Kojicic M, Li G, Cartin-Ceba R, Alvarez CT, Kashyap R, Dong Y, Poulose JT, Herasevich V, Garza JA, Gajic O (2011) Timing of the onset of acute respiratory distress syndrome: a population-based study. Respir Care 56:576-582

6. Force ADT, Ranieri VM, Rubenfeld GD, Thompson BT, Ferguson ND, Caldwell E, Fan E, Camporota L, Slutsky AS (2012) Acute respiratory distress syndrome: the Berlin definition. JAMA 307:2526-2533

7. Bernard GR, Artigas A, Brigham KL, Carlet J, Falke K, Hudson L, Lamy M, Legall JR, Morris A, Spragg R (1994) The American-European Consensus Conference on ARDS. Definitions, mechanisms, relevant outcomes, and clinical trial coordination. Am J Respir Crit Care Med 149:818-824

8. Kallet RH, Alonso JA, Pittet JF, Matthay MA (2004) Prognostic value of the pulmonary dead-space fraction during the first 6 days of acute respiratory distress syndrome. Respir Care 49:1008-1014

9. Seah AS, Grant KA, Aliyeva M, Allen GB, Bates JHT (2011) Quantifying the roles of tidal volume and PEEP in the pathogenesis of ventilator-induced lung injury. Ann Biomed Eng 39:1505-1516

10. Steinberg JM, Schiller HJ, Halter JM, Gatto LA, Lee HM, Pavone LA, Nieman GF (2004) Alveolar instability causes early ventilator-induced lung injury independent of neutrophils. Am J Respir Crit Care Med 169:57-63

11. Halter JM, Steinberg JM, Gatto LA, DiRocco JD, Pavone LA, Schiller HJ, Albert S, Lee HM, Carney D, Nieman GF (2007) Effect of positive end-expiratory pressure and tidal volume on lung injury induced by alveolar instability. Crit Care 11:R20

12. Andrews PL, Shiber JR, Jaruga-Killeen E, Roy S, Sadowitz B, OToole RV, Gatto LA, Nieman GF, Scalea T, Habashi NM (2013) Early application of airway pressure release ventilation may reduce mortality in high-risk trauma patients: a systematic review of observational trauma ARDS literature. J Trauma Acute Care Surg 75:635-641

13. Roy S, Sadowitz B, Andrews P, Gatto LA, Marx W, Ge L, Wang G, Lin X, Dean DA, Kuhn M, Ghosh A, Satalin J, Snyder K, Vodovotz Y, Nieman G, Habashi N (2012) Early stabilizing alveolar ventilation prevents acute respiratory distress syndrome: a novel timing-based ventilatory intervention to avert lung injury. J Trauma Acute Care Surg 73:391-400

14. Roy S, Habashi N, Sadowitz B, Andrews P, Ge L, Wang G, Roy P, Ghosh A, Kuhn M, Satalin J, Gatto LA, Lin X, Dean DA, Vodovotz Y, Nieman G (2013) Early airway pressure release ventilation prevents ARDS-a novel preventive approach to lung injury. Shock 39:28-38

15. Jia X, Malhotra A, Saeed M, Mark RG, Talmor D (2008) Risk factors for ARDS in patients receiving mechanical ventilation for $>48 \mathrm{~h}$. Chest 133:853-861

16. Kollisch-Singule M EB, Smith B, Ruiz C, Roy S, Meng Q, Jain S, Satalin J, Snyder K, Ghosh A, Marx W, Andrews P, Habashi N, Nieman G, Gatto LA (2014) Airway pressure release ventilation (APRV) reduces conducting airway micro-strain in lung injury. JACS 219:968-76

17. Pavone L, Albert S, DiRocco J, Gatto L, Nieman G (2007) Alveolar instability caused by mechanical ventilation initially damages the nondependent normal lung. Crit Care 11:R104

18. Baumgardner JE, Markstaller K, Pfeiffer B, Doebrich M, Otto CM (2002) Effects of respiratory rate, plateau pressure, and positive end-expiratory pressure on PaO2 oscillations after saline lavage. Am J Respir Crit Care Med 166:1556-1562

19. Formenti F, Chen R, McPeak H, Matejovic M, Farmery AD, Hahn CE (2014) A fibre optic oxygen sensor that detects rapid PO2 changes under simulated conditions of cyclical atelectasis in vitro. Respir Physiol Neurobiol 191:1-8

20. Caltabeloti F, Monsel A, Arbelot C, Brisson H, Lu Q, Gu WJ, Zhou GJ, Auler JO, Rouby JJ (2014) Early fluid loading in acute respiratory distress syndrome with septic shock deteriorates lung aeration without impairing arterial oxygenation: a lung ultrasound observational study. Crit Care 18:R91

21. Del Sorbo L, Slutsky AS (2011) Acute respiratory distress syndrome and multiple organ failure. Curr Opin Crit Care 17:1-6

22. ARDSnet (2000) Ventilation with lower tidal volumes as compared with traditional tidal volumes for acute lung injury and the acute respiratory distress syndrome. The Acute Respiratory Distress Syndrome Network. The New England journal of medicine 342:1301-1308

23. Tsuchida S, Engelberts D, Peltekova V, Hopkins N, Frndova H, Babyn P, McKerlie C, Post M, McLoughlin P, Kavanagh BP (2006) Atelectasis causes alveolar injury in nonatelectatic lung regions. Am J Respir Crit Care Med 174:279-289

24. Halter JM, Steinberg JM, Schiller HJ, DaSilva M, Gatto LA, Landas S, Nieman GF (2003) Positive end-expiratory pressure after a recruitment maneuver prevents both alveolar collapse and recruitment/derecruitment. Am J Respir Crit Care Med 167:1620-1626

25. Fan E, Wilcox ME, Brower RG, Stewart TE, Mehta S, Lapinsky SE, Meade MO, Ferguson ND (2008) Recruitment maneuvers for acute lung injury: a systematic review. Am J Respir Crit Care Med 178:1156-1163

26. Hodgson C, Keating JL, Holland AE, Davies AR, Smirneos L, Bradley SJ, Tuxen D (2009) Recruitment manoeuvres for adults with acute lung injury receiving mechanical ventilation. Cochrane Database of Systematic Reviews, Issue 2. Art. No.: CD006667. DOI: 10.1002/14651858.CD006667.pub2.

27. Ferguson ND, Cook DJ, Guyatt GH, Mehta S, Hand L, Austin P, Zhou Q, Matte A, Walter SD, Lamontagne F, Granton JT, Arabi YM, Arroliga AC, Stewart TE, Slutsky AS, Meade MO, Investigators OT, Canadian Critical Care Trials G (2013) High-frequency oscillation in early acute respiratory distress syndrome. N Engl J Med 368:795-805

28. Young D, Lamb SE, Shah S, MacKenzie I, Tunnicliffe W, Lall R, Rowan K, Cuthbertson BH, Group OS (2013) High-frequency oscillation for acute respiratory distress syndrome. N Engl J Med 368:806-813

29. Grasso S, Stripoli T, De Michele M, Bruno F, Moschetta M, Angelelli G, Munno I, Ruggiero V, Anaclerio R, Cafarelli A, Driessen B, Fiore T (2007) ARDSnet ventilatory protocol and alveolar hyperinflation: role of positive end-expiratory pressure. Am J Respir Crit Care Med 176:761-767

30. Talmor D, Sarge T, Malhotra A, O'Donnell CR, Ritz R, Lisbon A, Novack V, Loring SH (2008) Mechanical ventilation guided by esophageal pressure in acute lung injury. N Engl J Med 359:2095-2104 
31. Ferguson ND, Frutos-Vivar F, Esteban A, Fernandez-Segoviano P, Aramburu JA, Najera L, Stewart TE (2005) Acute respiratory distress syndrome: underrecognition by clinicians and diagnostic accuracy of three clinical definitions. Crit Care Med 33:2228-2234

32. Bikker IG, Leonhardt S, Reis Miranda D, Bakker J, Gommers D (2010) Bedside measurement of changes in lung impedance to monitor alveolar ventilation in dependent and non-dependent parts by electrical impedance tomography during a positive end-expiratory pressure trial in mechanically ventilated intensive care unit patients. Crit Care 14:R100

33. Muders T, Luepschen H, Zinserling J, Greschus S, Fimmers R, Guenther U, Buchwald M, Grigutsch D, Leonhardt S, Putensen C, Wrigge H (2012) Tidal recruitment assessed by electrical impedance tomography and computed tomography in a porcine model of lung injury*. Crit Care Med 40:903-911

34. Blankman P, Hasan D, Erik G, Gommers D (2014) Detection of 'best' positive end-expiratory pressure derived from electrical impedance tomography parameters during a decremental positive end-expiratory pressure trial. Crit Care 18:R95

35. Talmor D, Sarge T, O'Donnell CR, Ritz R, Malhotra A, Lisbon A, Loring SH (2006) Esophageal and transpulmonary pressures in acute respiratory failure. Crit Care Med 34:1389-1394

36. Loring SH, Pecchiari M, Della Valle P, Monaco A, Gentile G, D’Angelo E (2010) Maintaining end-expiratory transpulmonary pressure prevents worsening of ventilator-induced lung injury caused by chest wall constriction in surfactant-depleted rats. Crit Care Med 38:2358-2364

37. Gattinoni L, Chiumello D, Carlesso E, Valenza F (2004) Bench-to-bedside review: chest wall elastance in acute lung injury/acute respiratory distress syndrome patients. Crit Care 8:350-355

38. Kollisch-Singule M, Emr B, Smith B, Roy S, Jain S, Satalin J, Snyder K, Andrews P, Habashi N, Bates J, Marx W, Nieman G, Gatto LA (2014) Mechanical Breath Profile of Airway Pressure Release Ventilation: The Effect on Alveolar Recruitment and Microstrain in Acute Lung Injury. JAMA Surg 149:1138-1145

39. Roy SK, Emr B, Sadowitz B, Gatto LA, Ghosh A, Satalin JM, Snyder KP, Ge L, Wang G, Marx W, Dean D, Andrews P, Singh A, Scalea T, Habashi N, Nieman GF (2013) Preemptive application of airway pressure release ventilation prevents development of acute respiratory distress syndrome in a rat traumatic hemorrhagic shock model. Shock 40:210-216

40. Emr B, Gatto L, Roy S, Satalin J, Ghosh A, Snyder K, Andrews P, Habashi N, Marx W, Ge L, Wang G, Dean D, Vodovotz Y, Nieman G (2013) Airway pressure release ventilation prevents ventilator-induced lung injury in normal lungs. JAMA Surg 148:1005-12

41. Nieman GF, Bredenberg CE, Clark WR, West NR (1981) Alveolar function following surfactant deactivation. J Appl Physiol 51:895-904

Submit your manuscript to a SpringerOpen ${ }^{\circ}$ journal and benefit from:

- Convenient online submission

- Rigorous peer review

- Immediate publication on acceptance

- Open access: articles freely available online

- High visibility within the field

- Retaining the copyright to your article

Submit your next manuscript at $>$ springeropen.com 